\title{
Gastronomia como vetor de desenvolvimento: um resgate histórico no município de São Borja
}

\author{
Gastronomy as vector development: A Historical rescue in São Borja
}

\section{Camila Nemitz Oliveira Saraiva}

Instituto Federal Farroupilha - IFRS - Farroupilha - Rio Grande do Sul - Brasil

\section{Flávia de Araújo Pedron}

Instituto Federal Farroupilha - IFRS - Farroupilha - Rio Grande do Sul - Brasil

\section{Aline Prestes Roque}

Instituto Federal Farroupilha - IFRS - Farroupilha - Rio Grande do Sul - Brasil

\section{Lurdes Marlene Seide Froemming}

Universidade Regional do Noroeste do estado do Rio Grande do Sul - UNIJUI - ljui - Rio Grande do Sul - Brasil

\begin{abstract}
Resumo: Resgatar a história da alimentação e rever o processo cultural gastronômico que ocorreu no município de São Borja é o principal objetivo deste artigo. O município é um dos povoados mais antigos do estado do Rio Grande do Sul, pois seu início se deu no período Jesuítico, por volta do ano de 1682. As questões alimentares e gastronômicas no município são pouco conhecidas, pois não existem pesquisas específicas na temática. Assim, o resgate é imprescindível para que se conheça a história da alimentação no município e trabalhá-la de forma que a gastronomia possa ser tida como um vetor de desenvolvimento local. Este trabalho tem caráter qualitativo/descritivo e para sua realização, utilizou-se a pesquisa bibliográfica e entrevistas. Após a pesquisa, conseguiu-se revificar a evolução da constituição da cultura gastronômica e sua participação no processo de desenvolvimento do município.
\end{abstract}

Palavras-chave: História. Gastronomia. São Borja.

\begin{abstract}
The main objective of this work is to rescue the history of the food and eating habits and to review the cultural gastronomic process in the city of São Borja - RS. This city is one of the most ancient settlements established in the state of Rio Grande do Sul, dating from the Jesuit colonization around 1682. Questions regarding the food and the history of the gastronomy in the city are little known, since there is no specific research on this subject. So, this rescue is crucial in order to know the history of the food and eating habits in the city, and to work with it so that the gastronomy may become a vector for the local development. This work has a qualitative/descriptive character and was carried by means of bibliographic research and interviews. With this research it was possible to revitalize the evolution and constitution of the gastronomic culture and its participation in the development of the city.
\end{abstract}

Keywords: History. Gastronomy. São Borja. 


\section{Introdução}

Os hábitos alimentares fazem parte da realidade de determinado grupo social e podem ser entendidos e compreendidos como fonte de identificação dos laços e de representações da cultura popular desse povo, além de ser uma fonte ampla para pesquisas que envolvem todos os processos relativos à cadeia de produção de alimentos. O fenômeno que estuda esses processos relativos à relação do homem com o alimento, à cultura alimentar de cada local e todos os fatos ligados a eles é chamado de gastronomia.

É um tema que está em voga. Nunca foi dada tanta atenção para a comida e suas interfaces como está acontecendo neste momento do século XXI. A gastronomia é cultura e faz parte do cotidiano das pessoas desde os tempos remotos; por isso, ela está sendo muito discutida e trata de assuntos como a relação dos alimentos com o modo de vida das pessoas, às mazelas da fome no mundo, o desperdício de alimentos e o efeito que ele causa no meio ambiente, os modos de preparo e as descobertas de novos ingredientes por chefs de cozinha, a apresentação de programas de culinária nos meios de comunicação, os efeitos dos alimentos na saúde humana, a industrialização, a modernização da agricultura e da pecuária, entre outros aspectos.

Chama-se a atenção para o fato de que este tema busca se afirmar através de raízes culinárias e da forma de se entender o desenvolvimento social, cultural e econômico através das manifestações culturais de um determinado território. A cozinha tradicional e popular está sendo reconhecida, atualmente, como fonte de cultura e um valioso patrimônio intangível da humanidade. Essas manifestações, normalmente são transmitidas de geração em geração e tendem a se modificar com o passar do tempo por um processo aberto e evolutivo que vai sendo recriado pela coletividade, tornando-se conhecidas como a cultura gastronômica de um determinado local ou de um determinado povo (SCHLÜTER, 2003).
Isso faz com que a cultura gastronômica de um local específico possa ser vista como um vetor de desenvolvimento socioeconômico e cultural. Mas para que isso se concretize, é necessário que as localidades conheçam sua história, sua cultura e trabalhem com elementos autênticos da localidade, valorizando as matérias primas e produtos locais. É com esse intuito que este estudo se propõem a revificar a evolução da constituição da cultura gastronômica e a sua participação no processo de desenvolvimento de São Borja, pois, o município precisa resgatar essa história para alavancar a gastronomia local.

Para a realização da pesquisa, utilizou-se como recursos metodológicos a pesquisa bibliográfica, que aborda aspectos da alimentação em São Borja ao longo do tempo e a gastronomia como um produto cultural. Também, utilizou-se entrevistas com historiadores, que são referenciados no texto como Historiador I e Historiador II, e com pessoas mais antigas da cidade, com o intuito de relembrar a alimentação em diferentes épocas na cidade.

\section{Relação entre alimentação, gastronomia e cultura gastronômica}

A alimentação constitui-se uma necessidade fisiológica básica para a sobrevivência do ser humano, de acordo com as necessidades humanas descritas por Maslow (GODOY; D'ÁVILA, 2009), mas também tem uma função simbólica e é considerada como uma fonte econômica, social, política e cultural de várias sociedades. Pode ser entendida e compreendida como fonte de identificação dos laços e das representações da cultura popular de diferentes povos, fonte de prazer e convivialidade entre as pessoas, além de uma fonte ampla para pesquisas que agregam todos os processos envolvidos nesta cadeia. É um diferenciador de classes e grupos sociais, contribuinte na construção da identidade cultural de diferentes populações, alimentando o corpo e promovendo certa forma de se viver, contemplando todas as suas especificidades e evolução através dos tempos (SOUZA, 2012). 
Nesse sentido, Trigo ressalta que:

Comer, em todas as culturas e civilizações, é mais do que garantir a sobrevivência cotidiana. Comer é um ato simbólico cultural, representa um estilo de vida, aprofunda relações familiares e sociais, enriquece 0 processo de construção do conhecimento, além de ser uma das maiores delícias da existência, talvez apenas superada pelo sexo ou pela amizade (2001, p. 11).

A existência humana, para Cascudo (2004, p. 17), decorre do binômio "Estômago e Sexo" ou "Fome e Amor", e alimentam o fato de que eles governam o mundo, o primeiro alimentando o corpo e o segundo garantindo a reprodução. Afirma que são duas necessidades primordiais para a manutenção da vida, porém, por mais que os dois possam ser traduzidos como momentos de prazer, as vontades sexuais podem ser adiadas, mas a fome não, ela deve ser saciada.

No cotidiano, todos os aspectos estão ligados à alimentação, conforme Thorn (2011), "há comidas que compartilhamos, comidas servidas apenas para o nosso gosto, comidas que hostilizam e, claro, comidas que abrem o apetite sexual", praticando atos de comensalidade e convivialidade que fazem parte deste ritual de se alimentar e de conviver.

Dependendo do ponto de vista e da área de estudo de cada pesquisador, a alimentação pode representar uma importante fonte ou objeto de pesquisas, como por exemplo, para a antropologia e para a sociologia, em que a alimentação apresenta-se como uma forma de se entender as relações entre grupos, classes e fenômenos sociais. Claude LéviStrauss, em sua obra 'Mitológicas' (1964 - 1971), estudou as relações dos povos indígenas brasileiros através dos mitos, tabus e hábitos de consumo dos alimentos e das técnicas de preparo utilizadas por estas tribos (CARNEIRO, 2003). O antropólogo francês afirmou, ainda, que os alimentos também servem para pensar e que a gastronomia pode apresentar-se como uma linguagem em que cada comunidade, grupo ou sociedade entende as suas mensagens conforme os signos particulares e familiares dentro delas, e a alimentação é uma linguagem, como a dos humanos que apresentam diferentes línguas, de acordo com cada cultura, a cozinha não se apresenta diferente, ou seja, ela é universal e diversa.

Brillat-Savarin (1995), por sua vez, calcou suas pesquisas na alimentação como uma fonte de prazer através dos sentidos, principalmente do gosto, e, além disto, remeteu à ideia de que a alimentação pode diferenciar grupos, comunidades, regiões ou países.

Historiadores, geógrafos e economistas podem entender a alimentação como fonte dos seus estudos baseados nas questões das grandes transformações da humanidade, começando pela descoberta do fogo, por exemplo, das guerras por alimentos, das grandes navegações em busca de especiarias, da pecuária e agricultura, que têm como principal objetivo saciar a fome no mundo, e que dependem dos fatores de clima, relevo e mão de obra para se desenvolverem, assim como todos os fatores econômicos e contemporâneos decorrentes das cadeias produtivas de alimentos, entre outros tantos exemplos que poderiam ser citados aqui.

Para os químicos e físicos, os processos que ocorrem dentro de uma cozinha são um prato cheio para seus estudos e, atualmente, podem-se estudar os processos decorrentes da composição de alimentos e dos mecanismos de calor e entre outros, pela gastronomia molecular. A área da saúde, atualmente, está muito focada na alimentação saudável, como forma de manter e equilibrar a mente e o corpo ou nas ervas medicinais, alimentos orgânicos, nutrientes e vitaminas que podem auxiliar em tratamentos ou ser causas de doenças.

As descobertas em Medicina sobre a correlação entre alimentação e saúde permitiram uma série de carências específicas, como a de ferro provocando a anemia (...). Da mesma maneira se desvendaram as enfermidades causadas por excessos alimentares específicos, como o de gorduras causando o colesterol em demasia (...). A descoberta das vitaminas, no século $\mathrm{XX}$, fundamentou cientificamente a causa de algumas destas deficiências alimentares e ampliou a compreensão da fisiologia e da nutrição (CARNEIRO, 2003, p. 13). 
Enfim, todos os setores e áreas de estudos encontram na alimentação uma ampla fonte de pesquisas. No final do século XVIII, Brillat-Savarin já afirmava que:

\begin{abstract}
A gastronomia é o conhecimento fundamentado de tudo o que se refere ao homem na medida em que ele se alimenta. Assim, é ela, a bem dizer, que move os lavradores, os vinhateiros, os pescadores, os caçadores e a numerosa família de cozinheiros, seja qual for o título ou a qualificação sob a qual disfarçam sua tarefa de preparar alimentos. A gastronomia pertence à História Natural, à Física, à Cozinha, ao Comércio e à Economia Política (...) a gastronomia governa a vida inteira do homem (1995, p.57-58).
\end{abstract}

Esta exposição remete-nos ao fenômeno que estuda a alimentação, a cultura alimentar, a todos os fatos e aspectos ligados a estes e a sua cadeia produtiva, que é chamado de gastronomia. A gastronomia pode ser definida, conforme Viera; Cândido (2000), como o estudo de todos os processos relacionados à alimentação, da arte culinária que é composta dos procedimentos, métodos e técnicas que são destinados a processar e transformar os alimentos na sua forma bruta e hostil, como a natureza os concede, e apresentá-los de maneira que se configurem como um prazer a todos os sentidos humanos, ao tato, ao paladar, à visão e ao olfato, preservando as características organolépticas desses alimentos e os aspectos culturais, sociais, políticos, econômicos, estéticos, entre outros, relativos à alimentação. Estuda a arte de cozinhar, sua história e evolução através dos tempos e visa à apreciação da boa comida que é capaz de proporcionar prazeres e mobilizar todos os sentidos (VIERA; CÂNDIDO, 2000).

Este tema está em voga, no momento. A comida e todos os seus aspectos nunca foram tão discutidos como estão sendo atualmente. É um assunto presente em todos os momentos das nossas vidas, basta ligar a televisão para verificar chefs de cozinha contando os segredos da alimentação, celebridades preparando seus pratos favoritos, filmes que ressaltam os hábitos alimentares, as livrarias com as prateleiras cheias de livros onde a gastronomia é o prato principal, enfim, é um assunto que está tomando conta dos meios de comunicação em massa e das preferências pessoais de cada indivíduo, isto tudo porque a comida é cultura e faz parte do dia a dia das pessoas (LORENTE, 2014).

Cada povo tem seus costumes, crenças e tradições quando se trata da gastronomia. Alguns apresentam restrições a certos alimentos, apresentam rituais quando se trata de outros insumos e até mesmo baseiam uma parte de sua cultura nas práticas alimentares (TOPEL, 2003). Araújo et al. (2005, p. 09) ressaltam a importância "da alquimia de odores, sabores, perfumes e cores do espetáculo que a gastronomia oferece para se estudar culturas e hábitos alimentares de nações, povos e etnias, da pré-história à pós-modernidade".

Gastal; Castrogiovanni (2003) discorrem acerca de que a humanidade só pode ser compreendida a partir de três planos: o da existência biológica, que advém do nosso lado animal; do plano da identidade, a qual está inserida a existência social, e as relações de trocas com outras pessoas e outros grupos; e do plano simbólico, que traz como fonte as mitologias, a religiosidade, os costumes, saberes e fazeres e produção artística e cultural dos povos.

No contexto simbólico, que está presente na humanidade desde os primórdios, na forma de ritos, rituais, crenças, saberes, hábitos e costumes, está presente a alimentação. Não apenas com suas características físicas, mas com valores que ressaltam e diferenciam a cultura dos diferentes povos que participam das relações sociais de determinada sociedade ou região (GASTAL, 2005).

A história humana e do mundo andam lado a lado e, muitas vezes, até se confundem com a da gastronomia, que vem se adaptando e se modificando com o passar dos tempos. 


\section{Contexto histórico e desenvolvimento da cultura gastronômica no município de São Borja}

A história de São Borja confunde-se em grande parte com a do Rio Grande do Sul, pois é considerada uma das civilizações mais antigas do Estado, tendo sido povoada ininterruptamente desde a sua fundação. Grandes e importantes eventos foram travados no município e seu histórico descreve nitidamente os períodos de desenvolvimento econômico, social e cultural do mesmo, os quais foram e ainda são parte importante para o desenvolvimento do Estado, do seu território local e do seu povo.

O primeiro dos Sete Povos das Missões Orientais foi fundado em 1682 e chamado de São Francisco de Borja, em homenagem ao seu padroeiro. Organizou-se, a partir da transmigração de índios guaranis que habitavam a redução de Santo Tomé (Argentina), na margem direita do Rio Uruguai, do Padre Francisco Garcia de Prada e da inserção de alguns índios pampeanos güenoas, yarós e minuanos, somando, na sua implantação, aproximadamente, 1.952 "almas" (RODRIGUES; PINTO; COLVERO, 2013).

Cada uma das famílias presentes na Redução de São Francisco de Borja recebeu uma pequena porção de terra para fornecer o abastecimento diversificado de alimentos para as pessoas presentes na sua casa. As demais áreas pertenciam a toda comunidade, sendo consideradas "terras de Deus", em que a sua produção, feita pelos índios da aldeia, era dividida pelas suas famílias. As técnicas de agricultura e pecuária foram ensinadas pelos jesuítas aos índios, de acordo com os relatos do Historiador I.

Os jesuítas e índios ainda desenvolviam uma importante atividade de subsistência e comércio, a pecuária. Quando fundaram a Redução de São Francisco de Borja, o gado encontrado no território era xucro e selvagem, e encontrava-se solto em grande quantidade pelos campos do Estado. Pela abundância de animais, a carne bovina tornou-se a base da alimentação indígena, além de aproveitarem o sebo e o couro.

Os hábitos alimentares, com base em Scalco (2014), eram muito simples. Outro alimento muito consumido na dieta indígena era resultado da atividade da pesca realizada pelos índios. Os peixes eram preparados assados em trempes de bambu (moquém) ou de pedra (tucuruva), defumados ou secos ao sol e depois socados com farinha de mandioca para fazer o pirão. Além disso, era preparado o ensopado de mandioca com peixe.

A mandioca era outro alimento bastante consumido na época e ainda hoje na região e em todo o Brasil. Também era consumida como farinha ou assada perto das brasas. Os temperos eram escassos, nesse período, e o sal, que não era utilizado, era substituído pelas cinzas do fogo, que servia como tempero (SCALCO, 2014).

A atividade de coleta e caça eram secundárias, porém não menos importante e os animais mais comuns de serem consumidos eram o veado, o tatu e o javali. Outras carnes vermelhas também eram caçadas ou criadas como aves, porcos e ovinos, e consumidas assadas ou com farinha de mandioca que era feita no pilão.

Outro alimento, produzido na Redução e bastante consumido, era o milho. Com esse cereal era feito o mingau e a canjica pilada, era assado na brasa, cozido ou feito como pipoca, ou, ainda, consumido em forma de uma bebida fermentada. Outras culturas eram produzidas para subsistência da aldeia, como trigo, algodão, linho, feijão e fumo, além de hortas e pomares.

Os hábitos dos jesuítas espanhóis foram se misturando com os dos indígenas, como o gosto pelas festas, a charcutaria com a linguiça, o chorizo, o puchero, a preparação de cozidos ensopados e a plantação de uvas para produção do vinho, conforme discorre o Historiador II. Porém, a maior contribuição desse povo para a cultura do país, do Estado, e de São Borja foi a pecuária, a introdução do gado bovino, ovino e caprino, na região dos pampas, bem como de equinos que eram usados nas batalhas, para auxiliar no trabalho rural e nas tropeadas. Os 
jesuítas ensinaram aos índios as técnicas de agricultura e criação desses animais citados, além dos hábitos e crenças religiosas.

$\mathrm{Na}$ época do tropeirismo, a base econômica de São Francisco de Borja é a pecuária, Rillo consente que 0 papel da pecuária no desenvolvimento de São Borja, desde 1801 até por volta de 1940, é o mais importante que qualquer outra atividade praticada no município, "a ponto de podermos arriscar a dizer, figuradamente, que São Borja assenta sobre as quatro patas do boi a sua história econômica-comunal, até pelo menos a introdução mais recente da lavoura intensivamaquinizada no município" (1982, p. 48). Nesse período, o núcleo e matriz social era a Estância, onde as tropas eram criadas em grande escala e, posteriormente, levadas pelos tropeiros até as charqueadas de Pelotas, Rosário do Sul e Santana do Livramento. Com o declínio da mineração no sudeste do país, no final do século XVIII, a atividade de tropeirismo começa a declinar também.

Os costumes alimentares dos portugueses foram adaptados à cultura alimentar do índio que já havia se transculturado com os espanhóis, formando uma cultura híbrida, que pode ser chamada de lusoindígena-espanhola. Em Portugal, o consumo do bacalhau é o que remete a identidade gastronômica do país. Segundo o discurso do Historiador I, quando chegaram à região de São Borja, adaptaram esse costume com a utilização dos peixes locais do rio Uruguai, que eram pescados, secos com sal e consumidos de diferentes maneiras.

Scalco destaca que a contribuição portuguesa para a gastronomia são-borjense aconteceu com a chegada dos lusos à região:

Com eles vieram as novas formas de atuar na cozinha, novas habilidades de preparar pratos, modalidades diferentes de dosar, temperar e conservar os alimentos. Trouxeram, eles, os utensílios para uso na cozinha, horário para refeições, ordem dos pratos a serem servidos e porções proporcionais de alimentos. A salga das carnes passou a ser conhecida e realizada - preciosa técnica que os portugueses dominavam para a sua conservação e que aqui era/é importante devido ao desenvolvimento da pecuária local (2014, p. 71).

Essas contribuições lusitanas foram somadas à rotina alimentar que já estava estabelecida na região, além disto, trouxeram diferentes tipos de queijo, azeite de oliva, presunto e vinhos, entre outros.

Os negros africanos chegam ao município, trazidos pelos seus senhores lusitanos donos das estâncias, para serem escravos e trabalharem nas lavouras e na criação do gado. Eles trouxeram hábitos que, também, foram incorporados à rotina diária da vida da população presente na região. Consumiam os miúdos bovinos e as partes menos nobres do boi, ovelha ou porco, que sobravam das casas dos senhores da casa grande, como a língua, o fígado, os miolos, o bucho, o mocotó, sangue, rins, tudo acompanhado de muita pimenta (Historiador II). Consumiam, ainda, ensopados com ossos bovinos engrossado com abóbora ou farinha de mandioca socada no pilão ou farinha de "cachorro" feita com milho catete. Como sobremesas, faziam doces de mandioca e abóbora e broas de polvilho com muita gordura.

Além das comidas consumidas pelas pessoas, existiam as comidas que eram oferecidas aos santos, feitas em dias especiais e com um capricho além do normal para agradecer e agradar seus orixás. Essas oferendas podiam ser fumo, cachaça, comidas a base de farinha de mandioca, a base de milho amarelo, moelas de frango, frutas e feijões, ovos, entre outras, dependiam do "gosto" de cada entidade.

Ainda durante o séc. XIX, aproximadamente entre 1886 e 1888, Rillo destaca que os escravos, no município, já haviam sido libertos, antes mesmo da Lei Áurea, e que a pecuária havia "deslanchado extraordinariamente (...). O comércio progredia, acontecendo a exportação de couros, charque, rapaduras e cachaça para outras regiões, de modo especial pelo Rio Uruguai com navegação semiregular" (1982, p. 22). O autor apresenta o Rio como uma das vias de escoamento dos insumos 
alimentares produzidos no município.

A partir do séc. $X X$, começam a chegar à região os imigrantes alemães, por volta de 1910. Esses imigrantes, colonos agricultores, desenvolveram a policultura do milho e do linho e introduziram novos hábitos alimentares, culturais e socioeconômicos à região (Historiador I).

Os alemães, vindos de outras regiões do Rio Grande do Sul, trouxeram seus hábitos e a sua contribuição para a formação da cultura e costumes alimentares são-borjenses, que até os dias de hoje, são identificados e consumidos no município. Trouxeram as cucas, o queijo colonial, o chucrute, o consumo em grande quantidade de batatas, de carne suína e de frango, as galinhadas, faziam chimias de frutas e de batata doce, que é conhecido como um doce pastoso adoçado com melaço de cana, difundiram as técnicas de preparo de embutidos como a linguiça, a salsicha e o salame, produziam e consumiam o chopp como bebida típica.

Os italianos também contribuíram para 0 desenvolvimento socioeconômico e cultural de São Borja. Chegaram ao local, oriundos de outras regiões do Estado, da mesma forma que os alemães, em busca de uma melhor qualidade de vida para suas famílias.

Esses imigrantes cultivavam nas roças a maioria dos produtos que consumiam, tinham hábitos alimentares simples. Alimentavam-se de pratos à base de milho, que era moído em moinhos movidos à água, de carne de porco e de frango, as leguminosas e verduras eram plantadas na horta como, por exemplo, o radite.

O prato mais consumido era a polenta, feita com farinha de milho no fogão à lenha e uma panela ou tacho de ferro, mexida com colher de madeira ou cabo de vassoura. Neste contexto o Historiador I, afirma que outro prato muito consumido, naquela época, era a fortaia, ovos mexidos, com salame, queijo e banha de porco. A carne bovina era pouco consumida pelos italianos, eles consumiam mais a carne suína e de frango, as quais eram fritas na sua própria gordura e conservadas em latas tapadas por banha para não estragarem com facilidade.

Trouxeram, ainda, o hábito do consumo do risoto, que foi adaptado para o preparo com os produtos presentes na "nova terra". Faziam as canjas de frango, as macarronadas com molho sugo, o bigole (macarrão rústico), o brot (pão feito com farinha de milho e banha de porco), produziam geleias com as frutas nativas e o melado de cana-deaçúcar, fabricavam e consumiam o vinho como bebida principal da sua dieta. Como sobremesa, utilizavam as frutas para fazerem os doces em calda, feitos em tachos de cobre.

Esses povos adaptaram-se muito bem aos costumes que já se faziam presentes na região e, ao mesmo tempo, influenciaram a cultura, os hábitos e tradições dos demais povos que já estavam estabelecidos em São Borja.

Com base na entrevista do Historiador I, no ano de 1913, ocorreu a implantação da via férrea que liga São Borja a Itaqui e a Uruguaiana. Esse marco foi importante para o desenvolvimento do comércio e escoamento da produção agrícola de um município ao outro e para a troca de culturas e convivência e integração entre essas comunidades. Esse escoamento era feito anteriormente por via fluvial, porém levava um tempo maior, era menos seguro e despedia valores mais altos. A partir de 1938, é que chegou a rede ferroviária que liga São Borja a Porto Alegre, o que aumentou o comércio e a importação e exportação de produtos entre estes centros urbanos.

Foi instalada, no interior do município, em 1920, a primeira empresa de produção de charque e produtos derivados da carne bovina, que se chamava Saladeiro Alto Uruguai (Historiador II). Era uma empresa que beneficiava a carne de gado fazendo a salga para resultar no charque, e produziam até carne enlatada. Estes produtos eram enviados para todas as regiões do país e ainda, eram exportados, principalmente para Argentina.

Em 1933, foi fundado em São Borja, pelo governo federal, o Campo de Multiplicação de Sementes de Cereais e Leguminosas, o qual foi dirigido pelo italiano Dr. Baglioni até 1944. Nesse ano, 
foi passado para o governo estadual e passou a categoria de Estação Experimental de Sementes em 1952.

Essa instituição foi responsável pela expansão da lavoura de linho que, em 1960, deu a São Borja o título de "Capital do Linho", sendo o maior produtor desse produto da América do Sul e alavancou a agricultura no município, porém a sua economia continuava baseada na pecuária (RILLO, 1982). Além da distribuição das sementes de linho, o Campo de Multiplicação de Sementes criou e desenvolveu sementes especiais adaptadas ao solo e clima da região de diferentes produtos como, por exemplo, trigo, alpiste, soja, milho, aveia, girassol, arroz e algodão.

A cultura do trigo prosperou em São Borja a partir de 1941/42 e, mais tarde, tomou o lugar do linho. No mesmo período, chegaram ao município famílias, de origem alemã e italiana, que eram orizicultoras, oriundas da cidade de Cachoeira do Sul (terra conhecida pela produção do arroz), as quais desenvolveram ainda mais o plantio de arroz, que já se fazia presente desde 1937.

Através das entrevistas com pessoas antigas da cidade, sabe-se que nos anos 40 e 50, a população que morava no meio rural era muito superior à urbana. Essas famílias plantavam e criavam o que comiam e compravam poucas coisas nos "armazéns". A base da alimentação era a carne, de boi, porco e ovelha. Essas eram preparadas assadas ou fritas na banha, pois na época não havia o azeite. Os complementos vinham da lavoura: mandioca, batata-doce, arroz, feijão e com a farinha de milho faziam polenta e canjica.

A canjica foi bastante citada como um prato que traz boas recordações. A canjica era consumida tanto doce, com leite e mel ou melado, quanto salgada, temperada e com carne. No que se refere aos doces e sobremesas, os mais consumidos eram o doce de abóbora, doce de leite, mogango com leite e batata com leite.

Nessa época, poucas matérias-primas eram compradas, basicamente o açúcar, o sal, erva-mate, e as vezes a farinha de trigo também. A alimentação era simples e saudável, pois como as famílias tinham um sistema de subsistência, todos os produtos eram naturais, o que influenciava na boa saúde das pessoas, segundo os entrevistados.

A cultura da soja também teve, e ainda tem, expressão na agricultura local, a qual deslanchou a partir de 1965 e hoje é a segunda maior lavoura presente no município. Era uma cultura de inverno que era intercalada com a cultura de verão do trigo.

Ainda nesta década de 60, começam a chegar ao município, os imigrantes árabes. Estes se destacaram e se destacam, ainda hoje, pelo desenvolvimento do comércio. Fundaram uma colônia árabe, porém seus hábitos alimentares e religiosos são cultivados apenas pelos descendentes da etnia, não tendo grande influência na cultura da sociedade local em geral.

Na década de 70, São Borja foi considerada como uma das maiores cidades produtoras de soja do Brasil, quando ganhou o título de "Capital da Produção" (SCALCO, 2014). Com esse título, percebeu-se que os estancieiros da região, especialistas na criação de gado bovino e ovino, estavam trocando suas atividades pela agricultura, tornando-se produtores de grãos (PADILHA; TRENTIN, s.d.).

Nas últimas décadas, a cultura do arroz é a que mantém a maior produção agrícola local e que gera insumos para $o$ beneficiamento e industrialização de grãos de diversas empresas instaladas no município. Tais processos de modernização e industrialização da agricultura foram transformando os aspectos sociais, econômicos e culturais da região.

A identificação cultural coletiva em São Borja, que foi sendo compartilhada pela população local, deriva de um conjunto de representações, hábitos, crenças e conhecimentos que foram sendo fundidas ou criadas entre os diferentes povos que formaram a história do município e formataram as práticas alimentares presentes. 


\section{Linha do tempo do desenvolvimento e da gastronomia em São Borja}

Esta linha do tempo, descrita em formato de quadro (quadro 07), versa sobre os principais períodos de desenvolvimento de São Borja, bem como os principais fatos que formaram a cultura gastronômica local. Ela se concretizou como sendo um resumo da descrição do histórico do município e das atividades realizadas no local.

Quadro: Períodos de desenvolvimento e da construção da cultura gastronômica do município de São Borja.

\begin{tabular}{|c|c|c|}
\hline ANO & AÇĀO DE DESENYOLYIMENTO & CULTURA GASTRONÔMICA \\
\hline 1682 & $\begin{array}{l}\text { Fundação de São Francisco de Boria pelos jesuítas espanhóis } \\
\text { e indigenas. }\end{array}$ & $\begin{array}{l}\text { Regime de subsistência e economia baseada na pecuária e } \\
\text { desenvolvimento de técnicas de agricultura, e trocas culturais. }\end{array}$ \\
\hline 1750 & Assinatura do Tratado de Madrid. & $\begin{array}{l}\text { Trocas culturais, destruiçẫo das aldeias, das plantaçốes e a } \\
\text { soltura do gado bovino. }\end{array}$ \\
\hline \multirow{2}{*}{1761} & Domínio espanhol novamente. & \multirow{2}{*}{ Comercializavam erva mate e produtos derivados da pecuária. } \\
\hline & Expulsão dos jesuítas do Brasil. & \\
\hline 1829 & Invasão de São Borja, declínio da comunidade. & $\begin{array}{l}\text { São Borja é saqueada e destruída, os invasores roubaram } \\
\text { tudo, até o gado. }\end{array}$ \\
\hline 1834 & $\begin{array}{l}\text { São Francisco de Borja foi elevada a condiçẫo de vila por } \\
\text { decisão imperial. }\end{array}$ & $\begin{array}{l}\text { Volta do comércio e exportaçẫo de produtos derivados dos } \\
\text { bovinos e erva mate. }\end{array}$ \\
\hline 1837 & São Borja passa a produtora e exportadora de linho. & Agricultura se desenvolvendo na região. \\
\hline 1887 & São Boria foi considerada como cidade ou município. & A pecuária continua sendo a base econômica no município. \\
\hline 1940 & Base econômica do município era a pecuária. & $\begin{array}{l}\text { A pecuária era a base econômica da São Borja. Grande } \\
\text { consumo de carne bovina e produtos derivados. }\end{array}$ \\
\hline
\end{tabular}





\begin{tabular}{|c|c|c|}
\hline \multirow{2}{*}{1942} & Chegaram ao município, familias orizicultoras. & \multirow{2}{*}{$\begin{array}{l}\text { Aumento das lavouras de arroz, diminuição da pecuária. Novas } \\
\text { trocas culturais alimentares. }\end{array}$} \\
\hline & $\begin{array}{l}\text { Base econômica do município passa a ser derivada da } \\
\text { agricultura. }\end{array}$ & \\
\hline 1950 & Aumento da produção de trigo tomando o lugar do linho & Agricultura se adapta a outra cultura. \\
\hline 1960 & São Borja foi reconhecido como município Capital do Linho. & $\begin{array}{l}\text { Descendentes colonos alemâes - produção máxima de arroz e } \\
\text { linho. }\end{array}$ \\
\hline 1965 & Deslanchou a produção da soja no município. & Aumento das plantaçốes de trigo, linho, soja e arroz. \\
\hline 1970 & $\begin{array}{l}\text { São Borja foi considerado como o município maior produtor } \\
\text { de soja do Brasil. }\end{array}$ & Ganhou o título de Capital da Produção \\
\hline \multirow{2}{*}{1997} & Inauguração da Ponte da Integraçâo. & \multirow{2}{*}{$\begin{array}{l}0 \text { arroz se tornou a maior lavoura de produção e a base da } \\
\text { economia do município. }\end{array}$} \\
\hline & Aumentou a renda do município, com a ADUANA. & \\
\hline 2011 & Abertura de cursos de gastronomia. & $\begin{array}{l}\text { Aumentou a preocupação com o contento cultural } \\
\text { gastronômico por parte de instituiçốes de ensino. }\end{array}$ \\
\hline 2015 & A base econômica do município é a agricultura. & $\begin{array}{l}\text { Produção de arroz tomou conta dos campos e do } \\
\text { beneficiamento de produtos alimentares no município. }\end{array}$ \\
\hline
\end{tabular}

Fonte: desenvolvido pelas pesquisadoras com base em Saraiva, 2015.

sobre as demais e formasse a cultura gastronômica do município.

As informações contidas no quadro acima evidenciam que a economia de São Borja sempre, desde a sua fundação, foi baseada na pecuária e na agricultura, que fizeram e fazem parte da cultura gastronômica local são-borjense e do desenvolvimento social, cultural e econômico do município.

\section{Conclusões}

As teias de relações humanas históricas desses diferentes povos, que colonizaram e imigraram para São Borja, o clima, o relevo e hidrografia da região acabaram por compor a identidade gastronômica, social e cultural do povo são-borjense, assim como, favoreceram as formas de subsistência desses indivíduos. Essas teias e os diversos fatores complexos, presentes no dia a dia, fizeram com que a alimentação do índio, do espanhol, do português, do alemão e italiano sobressaísse
Os índios marcaram a cultura gastronômica local através do consumo da erva mate, da mandioca, do peixe do rio Uruguai e da técnica de preparo do churrasco, os espanhóis através da pecuária e do consumo de carne bovina e ovina, e os portugueses com suas técnicas de salga, desidratação e conservação dos alimentos (charque), os alemães com as culturas agrícolas e técnicas de embutidos que trouxeram e os italianos com as comidas mais consumidas no dia a dia, como massas, polentas e risoto, entre outros. Esses hábitos alimentares caracterizam as identidades são-borjenses e encontram-se presentes na realidade gastronômica do município até os dias de hoje. Resume-se que não existe um traço gastronômico e cultural identitário único em São Borja, mas sim traços e identidades diversificadas que se fundiram e formaram uma cultura híbrida que, atualmente, é reconhecida pelos munícipes, como identidade missioneira. 
Esses processos foram detectados pelo fato de que a gastronomia é pautada nos hábitos e costumes alimentares que foram construídos com 0 passar do tempo pelas pessoas que fizeram parte efetiva da história da cidade, acompanhando a evolução dos aspectos econômicos, sociais, culturais, políticos e ambientais. Sendo assim, a gastronomia pode até voltar às origens, porém não volta totalmente, pois há o desenvolvimento dessa sociedade e dos fatores citados anteriormente, que estão sempre em movimento, lembrando que as possibilidades de mudanças e adaptações não se esgotam.

Se os conceitos de desenvolvimento local e de relações sociais, afirmam que o principal objetivo do primeiro é o de proporcionar uma melhor qualidade de vida para as pessoas inseridas em determinadas sociedades, considera-se que a gastronomia é um vetor de desenvolvimento para o município de São Borja, na medida em que sua economia é baseada na agricultura e na pecuária, que pode se identificar no seu contexto histórico que os momentos principais de evolução desta sociedade estão pautados nessas bases econômicas e gastronômicas presentes no local. Bem como, percebe-se 0 envolvimento e interesse de participação dos atores locais nas suas manifestações sociais e culturais que desenvolvem suas capacidades de trabalho em grupo, visando a objetivos benéficos para toda a sociedade, que derivam dos aspectos gastronômicos promulgados com o passar do tempo. Aspectos esses que identificam a cultura alimentar são-borjense.

Foi concluído, com o entendimento do contexto histórico do desenvolvimento no município e - tracejar de uma linha histórica comparativa entre este aspecto e o percurso da cultura gastronômica local, que esses fatores estão intrinsecamente interligados, pois no município, desde a sua fundação as principais atividades econômicas, sociais e culturais estão baseadas nos hábitos agrícolas e pecuários desenvolvidos no local. E a gastronomia estuda e é composta de todas as etapas que fazem parte da cadeia dos alimentos e a sua relação com o homem, pode-se concluir que ela é marcante e determinante para o desenvolvimento do município.

Para finalizar, sente-se o dever de sugerir a realização de futuros estudos sobre 0 tema desenvolvimento, cultura e gastronomia em São Borja que podem levar a novos resultados. Além da necessidade de pesquisas mais aprofundadas sobre a história da alimentação e cultura gastronômica que complemente essa pesquisa, sugere-se estudos sobre as agroindústrias, pequenos produtores e agricultores familiares presentes no município, que muito contribuem para o desenvolvimento e subsistência da região. Assim como, estudos mais aprofundados sobre aspectos turísticos e dos patrimônios materiais e imateriais presentes na região. Outra hipótese é a realização de pesquisas sobre os restaurantes e bares do Cais do Porto, que fazem parte da história do município.

\section{Referências}

ARAÚJO, Wilma Maria Coelho et.al. Da Alimentação à Gastronomia. Brasília: UnB, 2005.

BRILLAT-SAVARIN, Jean Anthelme. A fisiologia do gosto. São Paulo: Cia. das Letras, 1995.

CARNEIRO, Henrique. Comida e Sociedade: uma história da alimentação. Rio de Janeiro: Campus, 2003.

CASCUDO, Luís da Câmara. História da Alimentação no Brasil. São Paulo: Ed. da Universidade de São Paulo, 1983.

História da Alimentação no Brasil. 3ạ. Ed. São Paulo: Global, 2004.

GASTAL, Susana.Turismo, imagens e imaginários. São Paulo: Aleph, 2005.

GASTAL, Susana; CASTROGIOVANNI, Antonio Carlos (organizadores). Turismo na pós-modernidade: (Des) Inquietações. Porto Alegre: EDIPUCRS, 2003. Coleção Comunicação, v. 25.

GODOY, Adelice Leite de; D'ÁVILA, César Kyn. Tutorial: a hierarquia das necessidades de Maslow Pirâmide de Maslow. CEDET - Centro de Desenvolvimento Profissional e Tecnológico, 2009. Disponível em: <http://www.cedet.com.br>. Acesso em: 10 nov. 2013.

LORENTE, Mariane. Cozinha pop. São Paulo: Panda Books, 2014. 
PADILHA, Paulo Roberto Paim; TRENTIN, Iran

Carlos Lovis. Reconstituição Sócio-Econômica da Região das Missões/RS. S.d. Disponível em: http://www.sober.org.br/palestra/12/100461.pdf.

Acesso em: 05.01.2015.

RODRIGUES, José Fernando Côrrea; PINTO, Muriel; COLVERO, Ronaldo Bernardino. Revista História Missioneira de São Borja: métodos para o ensino do patrimônio cultural. São Borja: Câmara de Vereadores de São Borja, 2013.

RILLO, Apparício Silva. São Borja em perguntas e respostas: monografia histórica e de costumes. 4 ed., n. 02. São Borja: Gráfica Noschang, 1982.

SARAIVA, Camila Nemitz Oliveira. Gastronomia, Cultura e Desenvolvimento: um estudo do município de São Borja. UNIJUÍ, 2015.

SCALCO, Maria Izabel Guimarães. Memórias, sabores e aromas. Alcance, 2014.

SCHLÜTER, Regina G. Gastronomia e turismo. São Paulo: Aleph, 2003.

SOUZA, Elaine Cristina de Melo Pereira. Alimentação como cerimônia indispensável do convívio humano. Trabalho de conclusão do Curso de Pós-graduação em Gestão de Projetos Culturais e Organização de Eventos, USP, São Paulo: CELACC/ECA, 2012.

THORN, Becky. Jantares de cinema: receitas dos seus filmes favoritos. Belo Horizonte: Gutenberg, 2011.

TOPEL, Marta F. As leis dietéticas judaicas: um prato cheio para a antropologia. Revista Horizontes Antropológicos. v. 9, n.19. Porto Alegre: URGS, 2003.

TRIGO, Luis Gonzaga Godoi. Apresentação. In: BARRETO, Ronaldo Lopes Pontes. Passaporte para o sabor: tecnologias para elaboração de cardápios. 2 ed. São Paulo: Editora Senac São Paulo, 2001.

VIERA, Elenara Viera de; CÂNDIDO, Indio. Glossário técnico: gastronômico, hoteleiro e turístico. Caxias do Sul: Educs, 2000. 